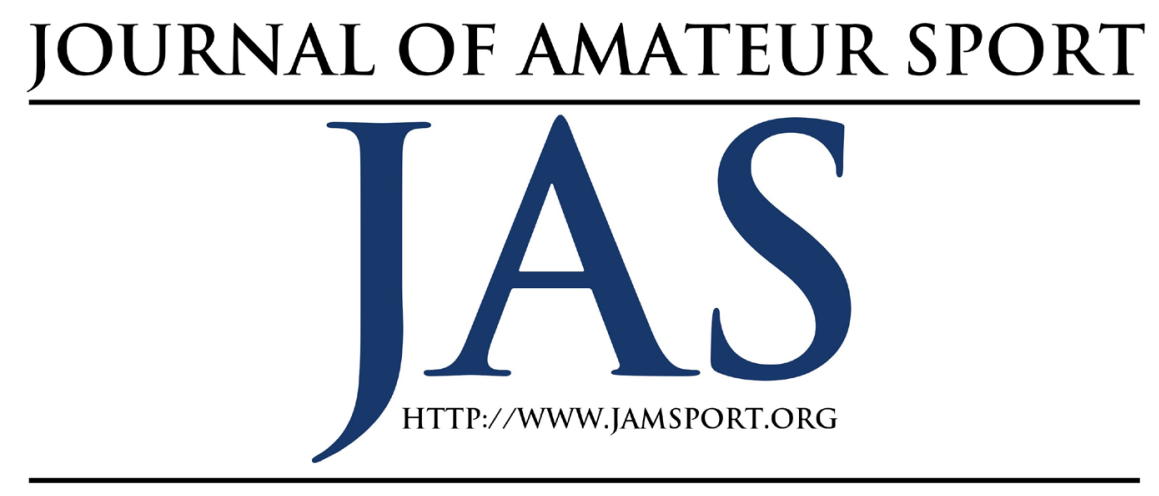

\title{
Female Volunteer Coaches in Community Sport: A Scoping Review and Research Agenda
}

\author{
Haley Baxter ${ }^{1}$ \\ Russell Hoye ${ }^{2}$
}

Pam Kappelides $^{2}$

\section{${ }^{1}$ University of Waterloo \\ ${ }^{2}$ La Trobe University}

\begin{abstract}
Over the past two decades there has been an increase in female sport participation in countries around the world, however, this has not been matched with an increase in the number of females volunteering to coach at the community level of sport. This paper uses a scoping review methodology to synthesize and analyze the extant research published on female volunteer community sport coaches, to identify gaps in the existing literature, and to provide directions for future research. It identifies a general lack of reported research on female volunteer coaches within community levels of sport and reports that existing research has focused on five themes: female volunteer coach motives, barriers, values, supports, and retention. The paper proposes a research agenda focused on seven key themes: policy and governance, coaching pathways, recruitment, retention, performance, stress and wellbeing, and support, as well as suggestions for research methods to explore these themes.
\end{abstract}

\section{Introduction}

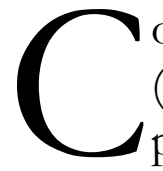

ommunity sport organizations

(CSOs) generally offer sport participation opportunities for people of all ages and can provide participants with physical and mental health benefits, enhanced well-being, social connection, and cohesion amongst mem- bers including volunteers (Krustrup \& Parnell, 2018; Misener \& Doherty, 2013; Stukas et al., 2014). Due to limited resources to pay staff CSOs rely on volunteers to run both recreational and competitive sport programs (Hoye et al., 2020). A significant proportion of CSO volunteers are coaches who play a crucial and distinct role in the management 
and front-line delivery of sport services (Harman \& Doherty, 2014). Despite the predominance of volunteer coaches in CSOs, there continues to be a lack of representation of female sport coaches at the community level, with the exception of certain sport activities where participation rates for females athletes are higher than that of males (e.g., netball, figure skating, gymnastics) (LaVoi, 2016).

Over the past two decades there has been a surge in female sport participation in countries around the world, however, the increase in sport participation and growth in demand for sport participation opportunities for girls and women has not been reflected in an increase in the number of females coaching sport at all levels and there continues to be significantly lower numbers of women pursuing volunteer coaching positions relative to males. For example, in Canada over $70 \%$ of girls aged $5-17$ actively participate in sport (Physical Activity Monitor Survey, 2010) but in 2015 , only $25 \%$ of all coaches in the Canadian sport system were female (Government of Canada, 2015). Of new Canadian coaches whom participated in the National Coaching Certification Program (NCCP), 30\% were female (Stirling et al., 2017). In voluntary roles younger Canadian females tend to outnumber men at lower youth levels of competition, yet increased representation of female coaches has not escalated to voluntary positions within high-performance sport (Reade et al., 2009).

Similarly, studies in Australia using the most recently available national data show that $70 \%$ of girls aged $15-17$ and $70 \%$ of women aged 24-35 participate in sport and physical recreation activities, yet men continue to be overrepresented in sport volunteer positions with twice the number of male volunteers in comparison to their female counterparts (Cuskelly, 2011). In England, $65 \%$ of volunteer coaches were male in comparison to $34 \%$ of females (Sport England, 2019). In New Zealand $89 \%$ of girls aged $15-18$ participate in sport and recreation, yet, Sport New Zealand's 2018-2019 annual report noted the underrepresentation of women in management, coaching, and governance roles and made it a strategic objective to focus on creating more gender balanced organisations (Sport New Zealand Group, 2019). In the United States female sport participation rates are increasing with just over $60 \%$ of grade twelve girls participating in sport (Women's Sport Foundation, 2018). The increase in participation is not reflected amongst sport volunteers with $9.3 \%$ of men volunteered as a coach, referee, or supervised sport teams in comparison to $2.7 \%$ of women (US Bureau of Labor Statistics, 2015).

There is clear underrepresentation of females in community coaching ranks as illustrated in the latest available data from Western, club-based sports systems in the UK, Canada, Australia and New Zealand. Research on the topic of female sport coaches has grown, especially over the last decade, as sport governing bodies and policy makers seek to address the lack of representation of females in coaching roles (LaVoi, et al., 2019). However, the majority of research in this area focuses on females in paid coaching roles at sub- 
elite or elite levels, using participants who are current or former professional level coaches within the American National Collegiate Athletic Association (NCAA), Canadian USport, and various national sport systems (e.g., Bruening \& Dixon, 2008; Dixon \& Sagas, 2007). These more high-profile female coaches are perhaps more easily identifiable and accessible for recruitment in research endeavors because of their formalized positions within sub-elite and elite levels of sport.

While recruitment of participants might be more of a challenge within the community sport sector, it is still of equal importance to study the underrepresentation of volunteer female coaches given the distinct nature and challenges faced by the non-profit sector in comparison to employed female coaches within private or public sectors. For example, the community sport systems in many countries including Canada, Australia, New Zealand, and England, do not have the resources or capacity to pay many of their coaches regardless of gender (Misener \& Doherty, 2013). Organizational stress is compounded by the difficulty CSOs face in recruiting and retaining volunteers, especially volunteer coaches (Cuskelly et al., 2006).

The importance of having females in coaching roles has been well documented (LaVoi \& Dutove, 2012; LaVoi, 2016). For most individuals, sport is initially, if not exclusively experienced as a participant at the recreational community level, with only a small proportion advancing to collegiate or professional sport. The lack of representation of female coach- es at the community level means most participants are not being exposed to female coaches. Young women tend to choose role-models in closer proximity than men, basing their choice on the relationship between themselves and the role model (Ronkainen et al., 2019). Female coaches who effectively foster positive coach-athlete relationships can guide positive development and model lifelong involvement in sport (Fraser-Thomas et al., 2007). Quality female coaching role models has also been positively associated with coaching self-efficacy beliefs and coaching interests amongst female athletes (Moran-Miller \& Flores, 2011). The absence of female role models is often noted as a barrier that females face to entering coaching roles (Everhart \& Chelladurai, 1998; LaVoi \& Dutove, 2012).

This scoping review focuses on exploring the extant literature devoted to volunteer female coaches at the community level of sport in order to synthesize and analyze the research published on female volunteer community sport coaches, to identify gaps in the existing literature, and to provide directions for future research.

\section{Methods and Analysis}

In comparison to a systematic review, a scoping review is a feasible and synthesized way to provide an overview of a field of research (Peterson et al., 2017). Scoping studies have been used in a wide array of disciplines and are commonly seen in the fields of medicine and public health (e.g. Hogan et al., 2017; Hudani \& Rojas-Fernandez, 2016; Quackenboss \& Tulve, 2016). In the sport management 
field, scoping studies are a relatively new methodological practice, but interest in the methodology has been growing in recent years (e.g. Dowling, Leopkey \& Smith, 2018; Inoue et al., 2015).

Often scoping reviews are defined in comparison to systematic reviews that have much more narrow parameters and clearly defined questions, with strict inclusion criteria primarily focused on high level studies (Arksey \& O’Malley, 2005; Peterson et al., 2017). In contrast, scoping studies allow for a more general question and are especially useful when literature in a particular area is diverse. Quantitative and qualitative research, theoretical and narrative reviews, and gray literature are considered acceptable for inclusion if the content is relevant to the focus of the review and is aligned with the research teams predetermined inclusion criteria (Peterson et al., 2017). A scoping review can help to draw conclusions, identify gaps in the literature, and be a first step that can act as the informational foundation necessary to move forward with future research (Peterson et al., 2017). In the context of the nascent state of research into female volunteer sport coaches at the community level, a scoping review will assist capture the diversity of published research without being limited to a specific question as for a systematic review.

Arksey and O'Malley (2005) provide the most widely accepted and highly cited six step methodological approach to conducting a scoping review; (1) Identifying the research question(s); (2) Identifying the relevant studies; (3) Study selec- tion; (4); Charting the data; (5) Collating, summarizing, and reporting the data; and (6) Consultation. In the sport management discipline, this is the most consistent scoping review framework employed (Inoue et al., 2015; Dowling et al., 2018), however the framework is not immune to critique. While the six steps provide a solid foundation, several authors noted a lack of detail on how to conduct each step, especially in regard to the data analysis process (Drey \& Gould, 2009; Levac et al., 2010). In response to Arksey and O'Malley's request for feedback on their proposed framework, Levac et al., (2010) undertook an assessment. This resulted in several recommendations to create transparency and enhance the rigour and quality of the framework, particularly in the data analysis and reporting phase. Until further methodological considerations emerge, Arksey and O'Malley's (2005) framework along with enhancements provided by Levac et al.,'s (2010) is recommended as the most useful and rigorous scoping review framework and will thus be used to guide this scoping review (Colquhoun et al., 2014). The following sections outline the method used for the review based on the six stages of this framework.

\section{Stage 1: Identification of Research Question}

In comparison to meta-analyses or systematic reviews which often have narrow parameters and more focused research questions, a scoping review allows for more general research questions to explore related literature (Arksey \& O’Malley, 2005). As such this review is 
guided by the following question: What is known from the existing literature about the involvement and experiences of female volunteer community sport coaches?

\section{Stage 2: Determination of Relevant Studies}

In order to provide a comprehensive overview of content related to female volunteer community sport coaches, literature was identified through three sources; electronic databases (SPORTDiscus, Scopus, Google Scholar, PsychInfo, Web of Science); a manual search of relevant sport management and sport psychology journals; and reference list inspections. A University Librarian, experienced in the design and conduct of scoping reviews, was consulted in order to develop an appropriate search strategy. The electronic database search terms "volunteer or volunteering or volunteerism" AND "female or girl or women or girls or females" AND "coach or coaching or coaches" yielded a total (16 461) hits (SPORTDiscus [145], Scopus [1716], Google Scholar [14 400] PsychInfo [27], and Web of Science [173]). The three major sport management journals (Journal of Sport Management, Sport Management Review, and European Sport Management Quarterly) as well as other relevant journals (e.g. International Journal of Sports Science and Coaching and Women in Sport and Physical Activity Journal) were also manually searched to capture further possible articles. Reference lists of articles identified through these search strategies were also inspected to ensure that other relevant articles were included. Websites of relevant organizations including national sport agencies and coaching associations (e.g., Sport Australia, Sport England, Coaching Association of Canada) and organizations focused on women in sport (e.g., Tucker Centre for Research on Girls and Women in Sport, Canadian Association for the Advancement of Women and Physical Activity (CAWWS), International Working Group of Women in Sport (IWG), Women in Sport Foundation), were also searched for resources referring to empirical research. This search strategy yielded 35 articles that were identified for possible inclusion in the review.

\section{Stage 3: Study Selection}

To remove studies unrelated to the purpose of the scoping review, the authors then independently conducted a full text review of all 35 articles initially identified for possible inclusion. The search was refined by only including peer-reviewed empirical research that focused on volunteer female coaches in the context of community sport, explicitly identified female coaches as part of the sample for the study and were published in English. If all three authors agreed that the article did not meet inclusion criteria, the article was excluded. This process resulted in a final list of 13 empirical research articles that focused specifically on female volunteer community sport coaches.

\section{Stage 4: Charting the Data \\ Data was charted using Excel. The charting approach followed a descrip-}


tive analytic method within the narrative tradition which informed Arksey and O'Malley's (2005) framework. This method involves collecting standard information from each study. Information collected from the studies in this review included the reference, research questions, sample, location, theoretical frameworks, method and findings for each study. Once charted, this data was used for analysis (see Table 1). Stage 5 (collating, summarizing, and reporting the data) and stage 6 (consultation) will be reported in the following finding and discussion sections.

\section{Findings and Discussion} Frequency Analysis Findings Sample, Location, Method:

The review generated a total of 13 peer-reviewed journal articles that met the inclusion criteria. The low number of studies identified is not surprising given that most of the research to date has focused on sub-elite, elite or inter-collegiate female coaches (LaVoi \& DuTove, 2012) and confirms claims that there remains a dearth of research on female coaches at the community level where volunteerism is more prevalent (LaVoi \& DuTove, 2012). Frequency analysis findings revealed the following descriptive characteristics. The studies were all conducted in western countries, including Canada $(\mathrm{N}=3)$, New Zealand $(\mathrm{N}=3)$, the United States $(\mathrm{N}=5)$, the United Kingdom (N=1) and Norway $(\mathrm{N}=1)$. With the exception of one article published in 1984, most articles were published in 2009 ( $\mathrm{N}=5)$ and thereafter $(\mathrm{N}=8)$. Studies were published in a wide range of academic journals from various disciplines including psychology, sport science and coaching, management, gender studies, and sociology.

The samples rarely focused solely on the population of female volunteer community sport coaches apart from Leberman and LaVoi's (2011) research on mother-coaches in youth sport. Often male coaches, administrators, paid coaches, or coaches from different levels (e.g. elite, inter-collegiate) were included in the overall study samples. Most studies used a sample of coaches from a mixture of different sports $(\mathrm{N}=9)$. Four studies sampled coaches from a single sport, including soccer $(\mathrm{N}=3)$ and volleyball $(\mathrm{N}=1)$. In general, the sample sizes of volunteer female coaches were small.

All studies were designed as cross-sectional studies. Methods used by the studies included qualitative $(\mathrm{N}=7)$, quantitative $(\mathrm{N}=4)$, and mixed methods $(\mathrm{N}=2)$. Qualitative studies followed relatively traditional data collection procedures. Semi-structured interviews $(\mathrm{N}=5)$ were the most popular method used for data collection followed by indepth interviews $(\mathrm{N}=2)$. None of the studies contributed to theory building, instead opting to take existing theory and apply it to the context of the study. The only studies to share the same theoretical framework were Allen and Shaw (2009/2013) who used self-determination theory as a framework for analysis. Despite the varied nature of articles included in the review, common themes emerged and are outlined in Table 1. 


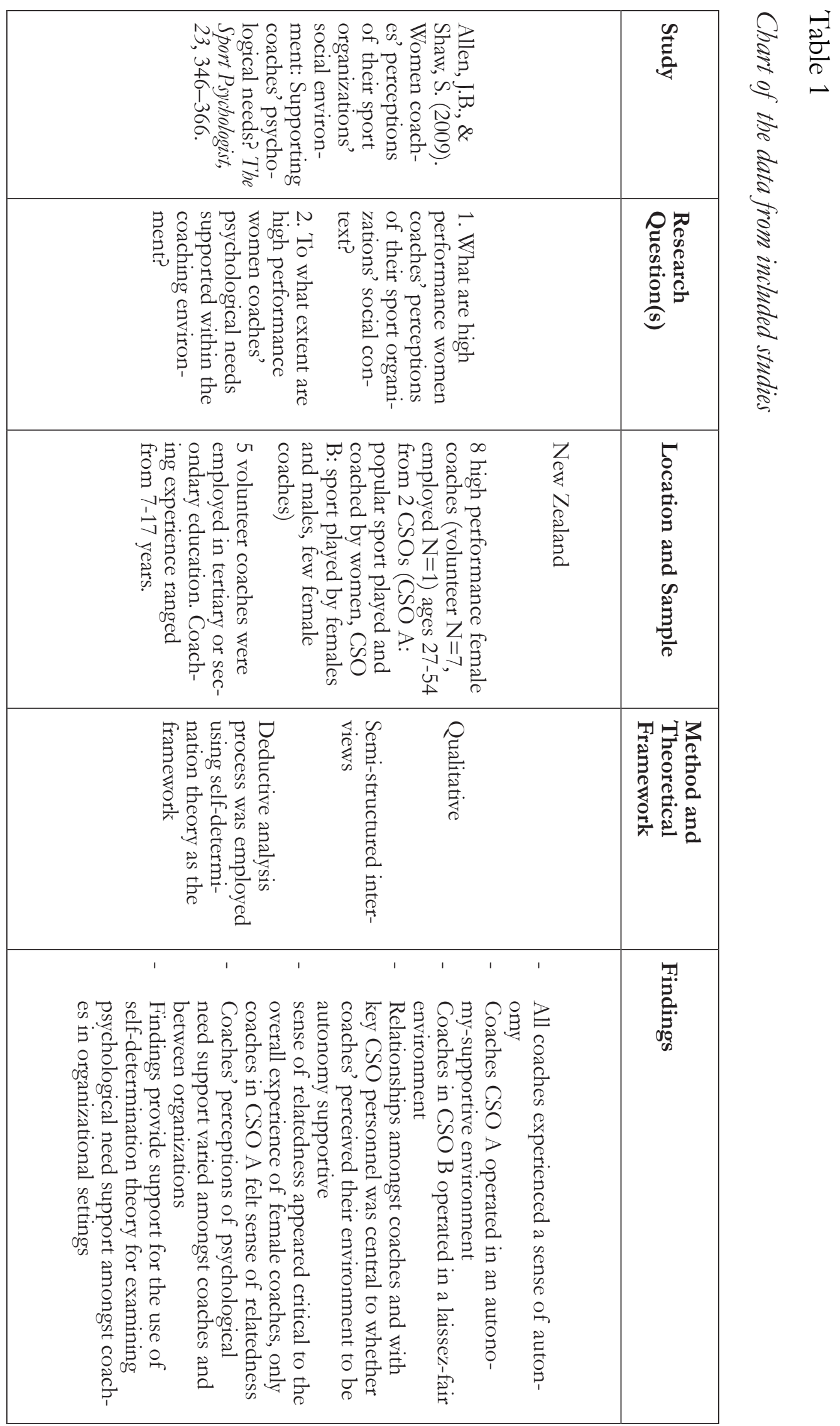

Journal of Amateur Sport Volume Seven, Issue One Baxter, 202170 


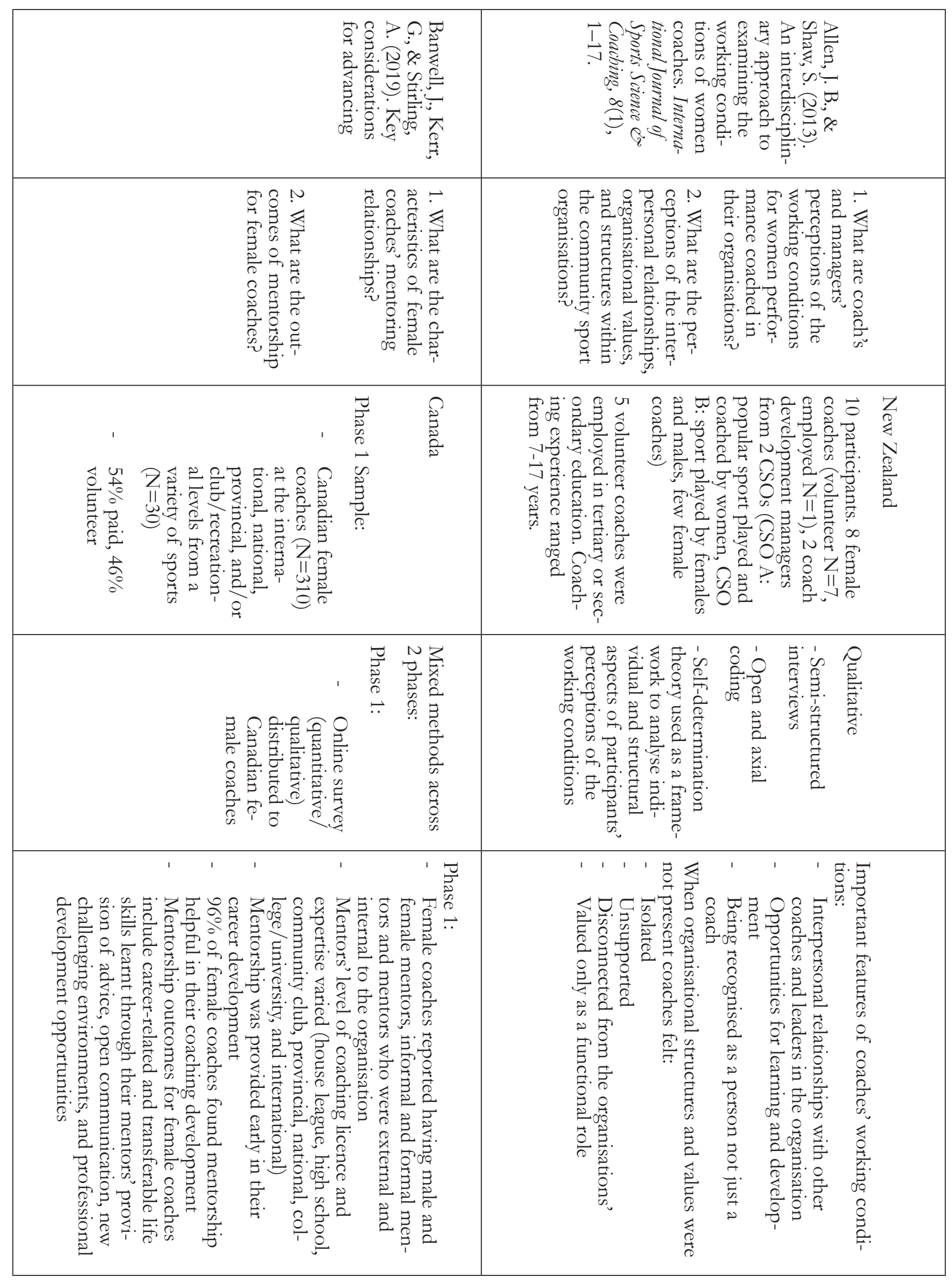




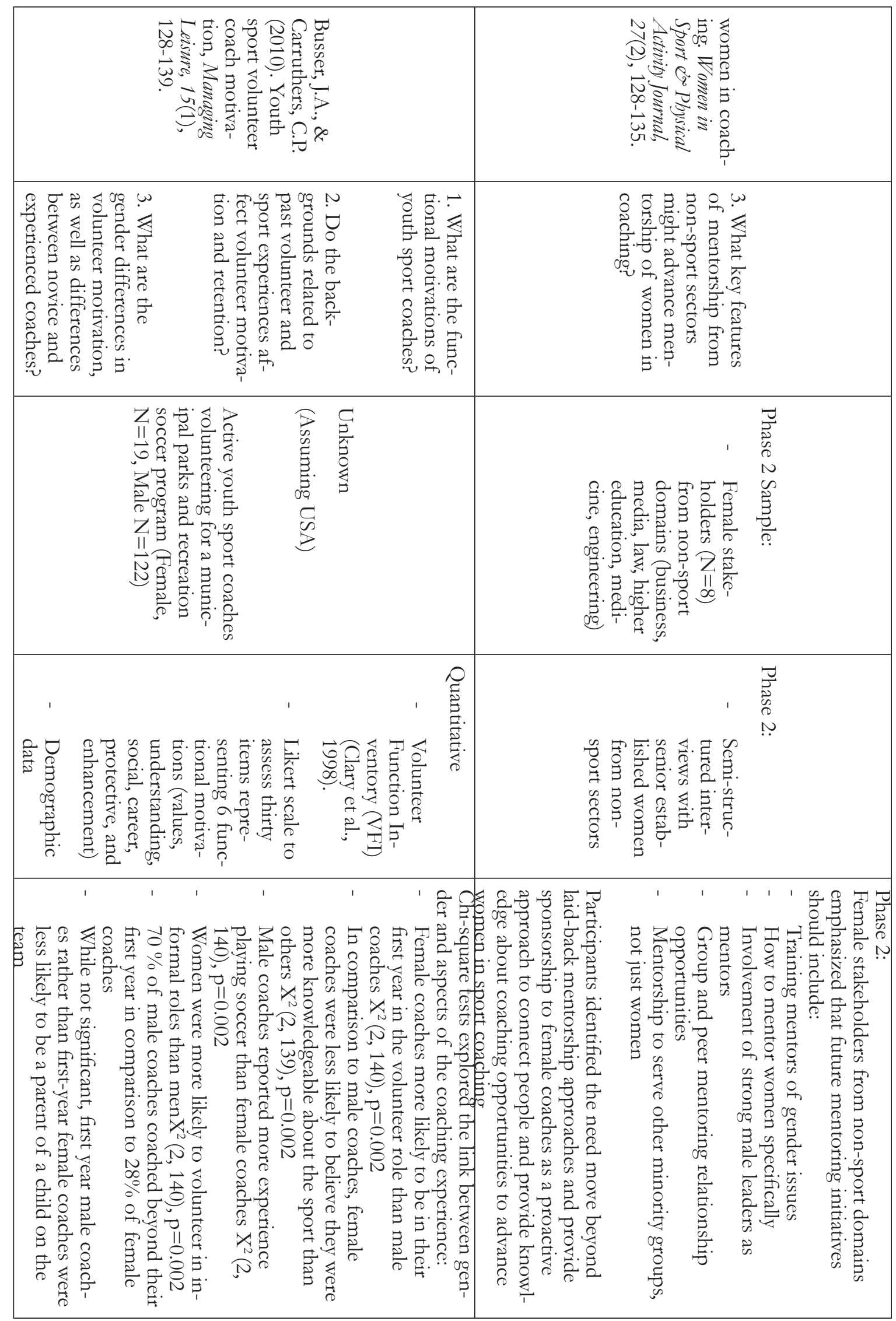

Journal of Amateur Sport Volume Seven, Issue One Baxter, 202172 


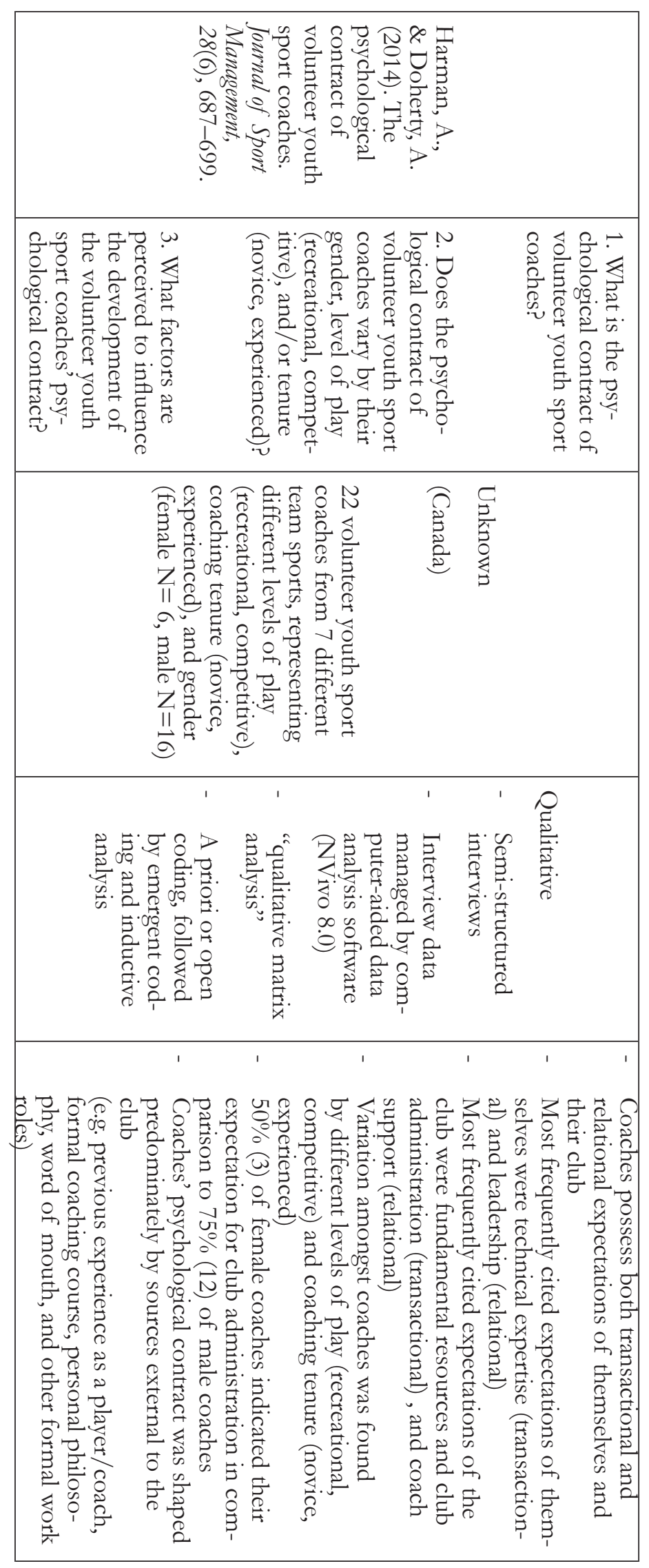




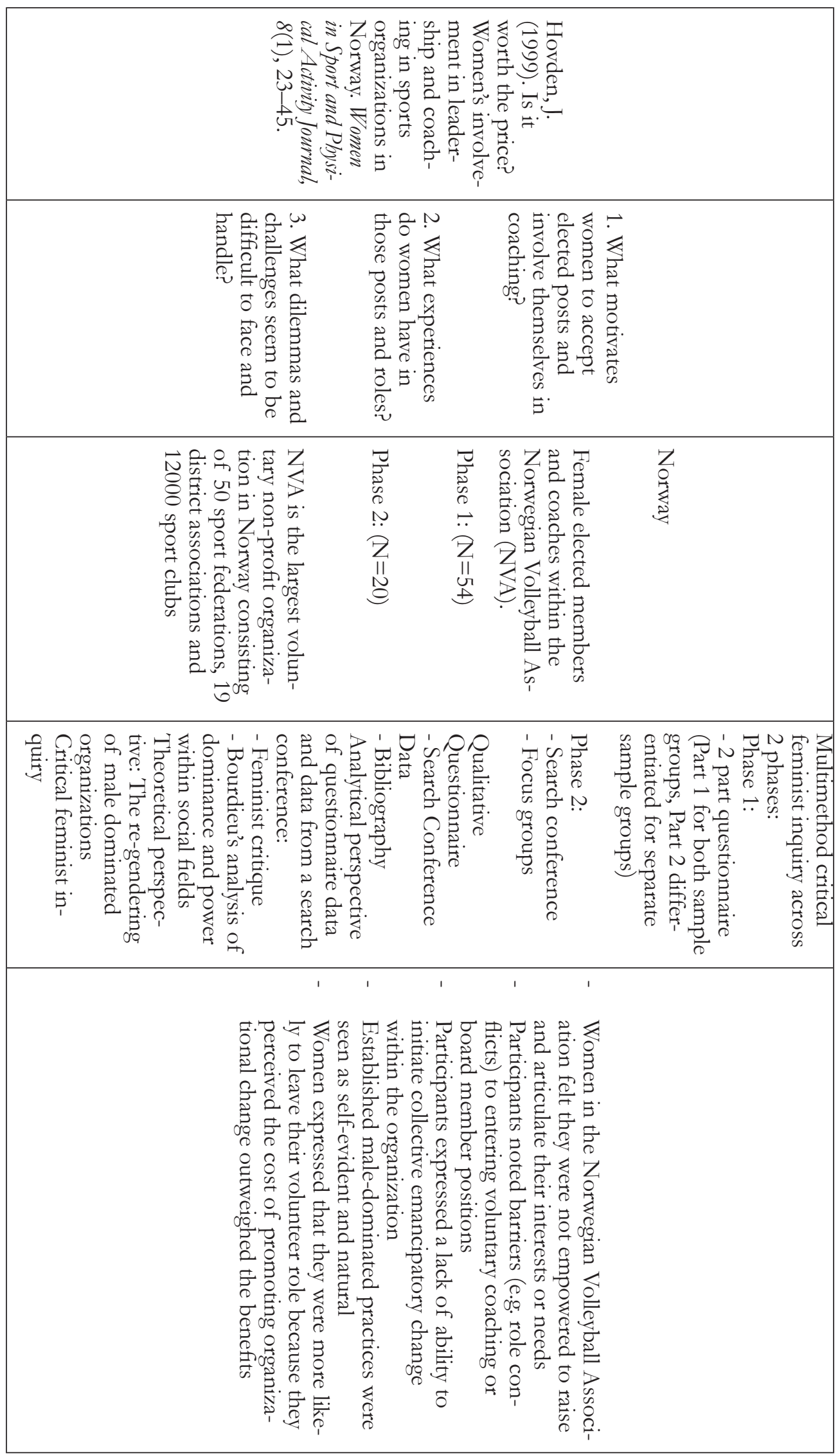

Journal of Amateur Sport Volume Seven, Issue One Baxter, 202174 


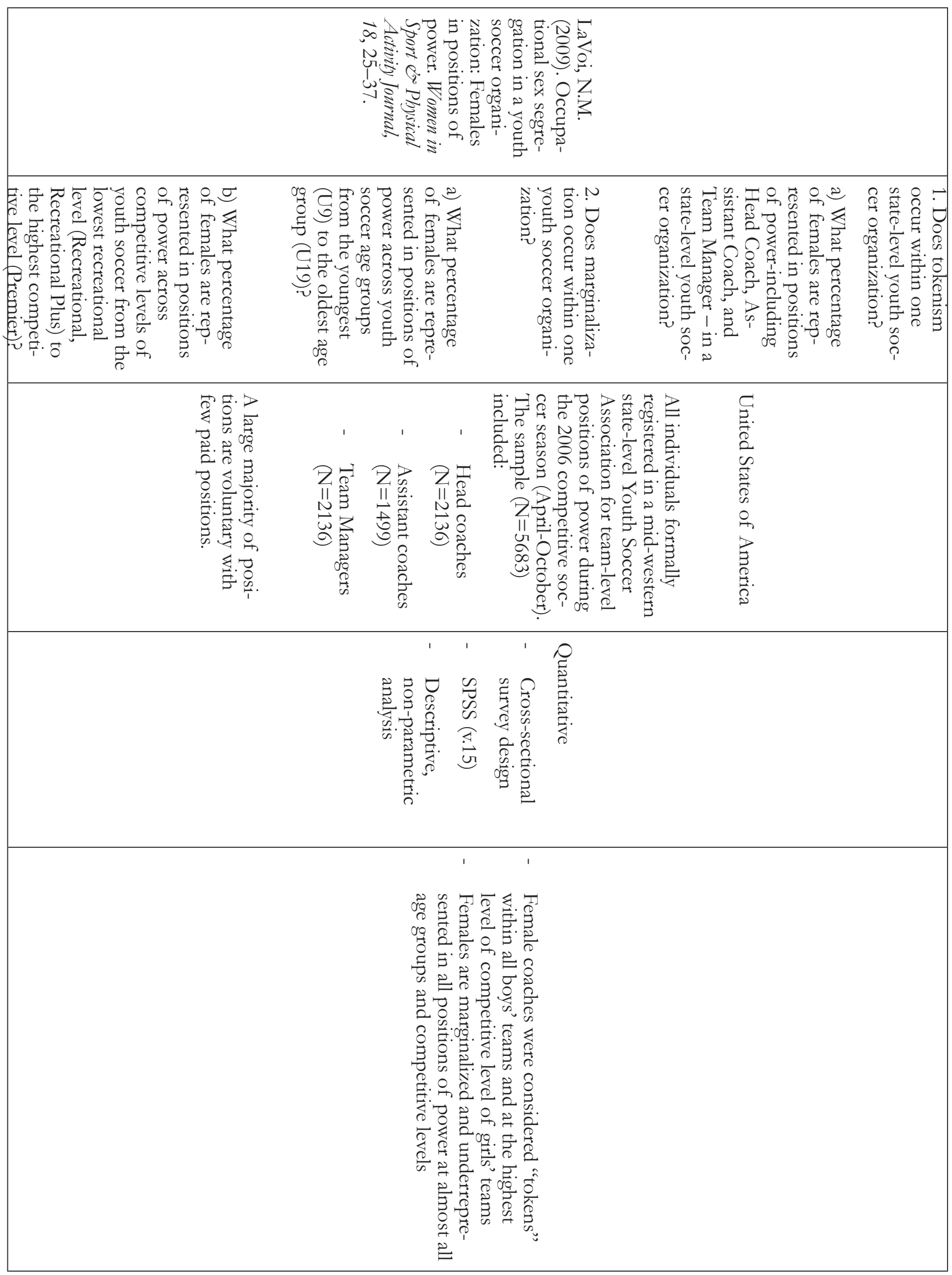

Journal of Amateur Sport Volume Seven, Issue One Baxter, 202175 


\begin{tabular}{|c|c|}
\hline 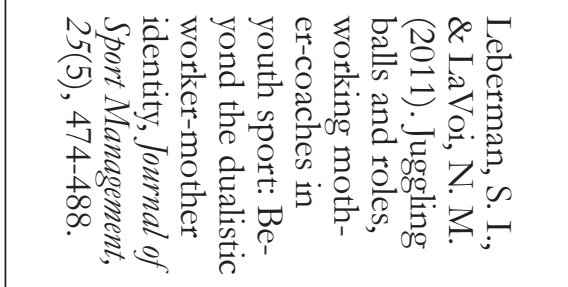 & 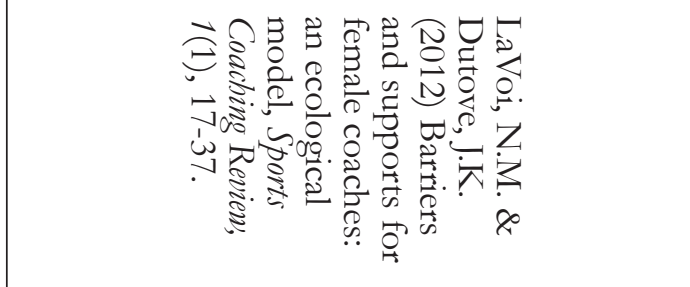 \\
\hline 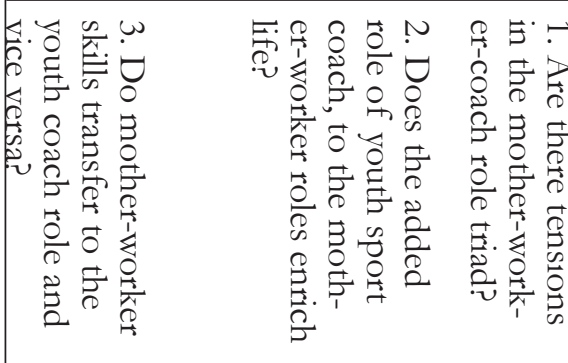 & 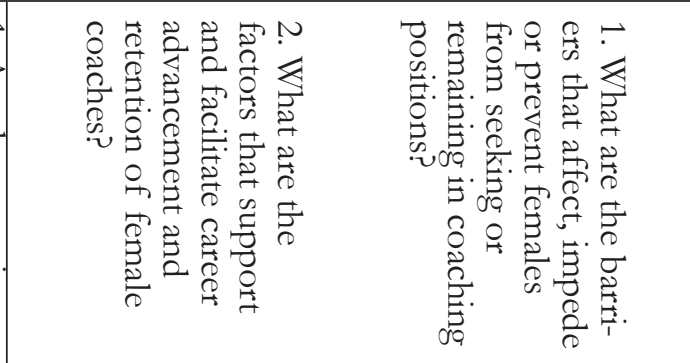 \\
\hline 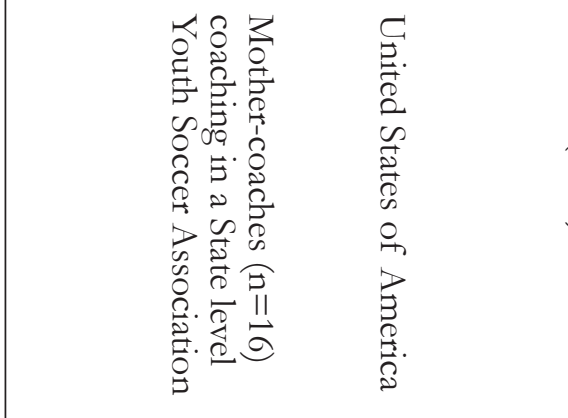 & 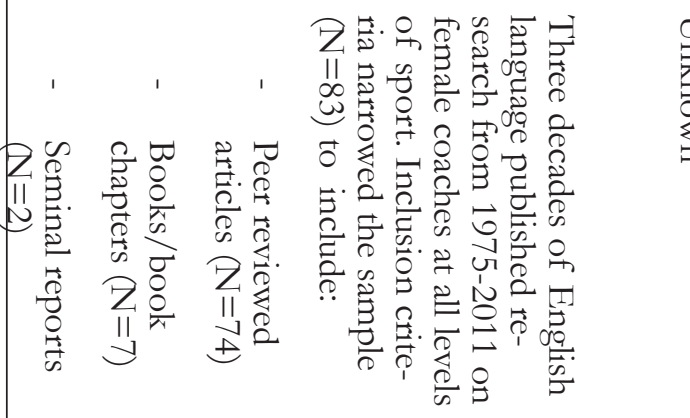 \\
\hline 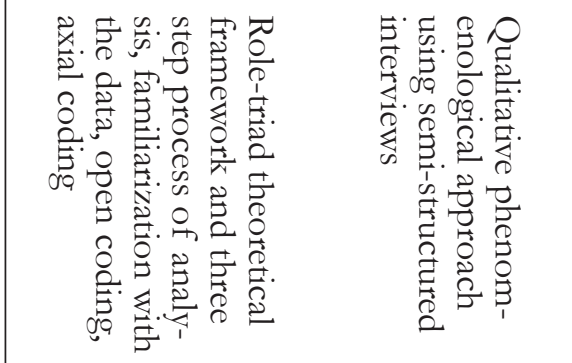 & 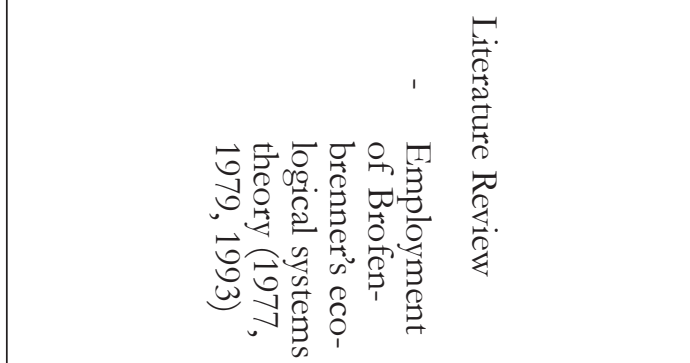 \\
\hline 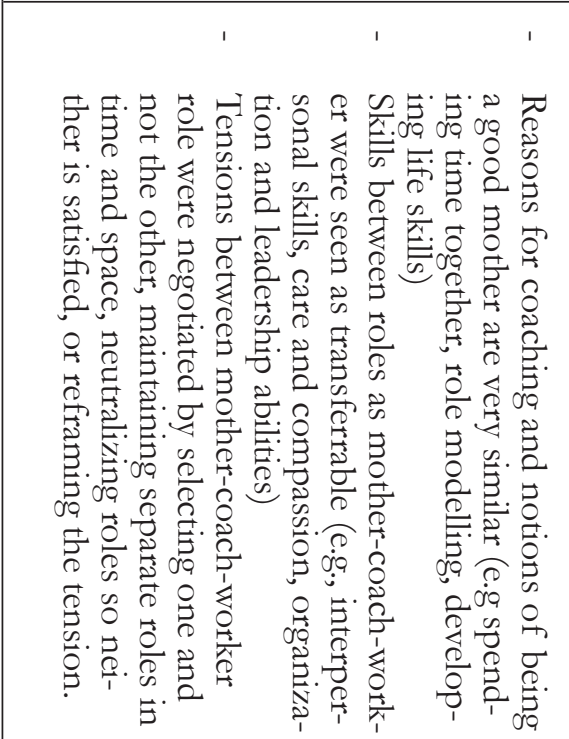 & 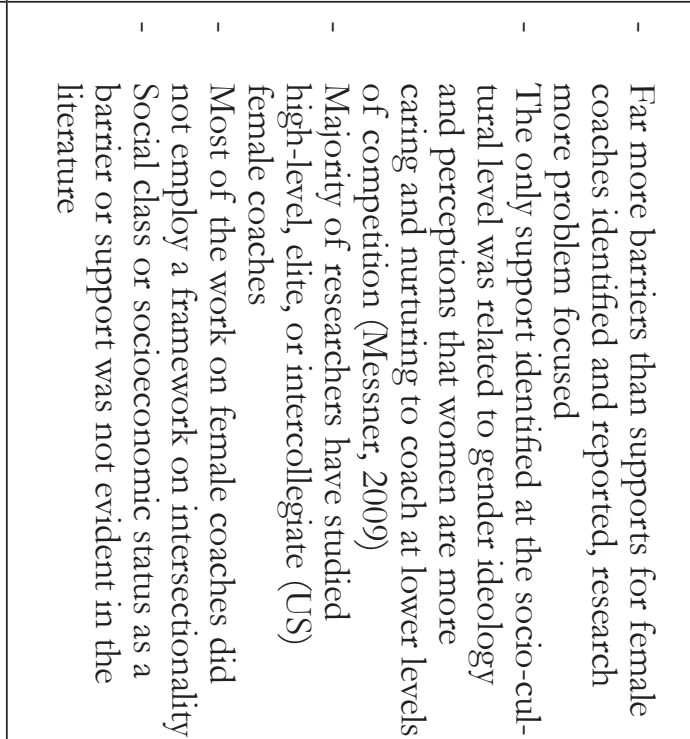 \\
\hline
\end{tabular}

Journal of Amateur Sport Volume Seven, Issue One Baxter, 202176 


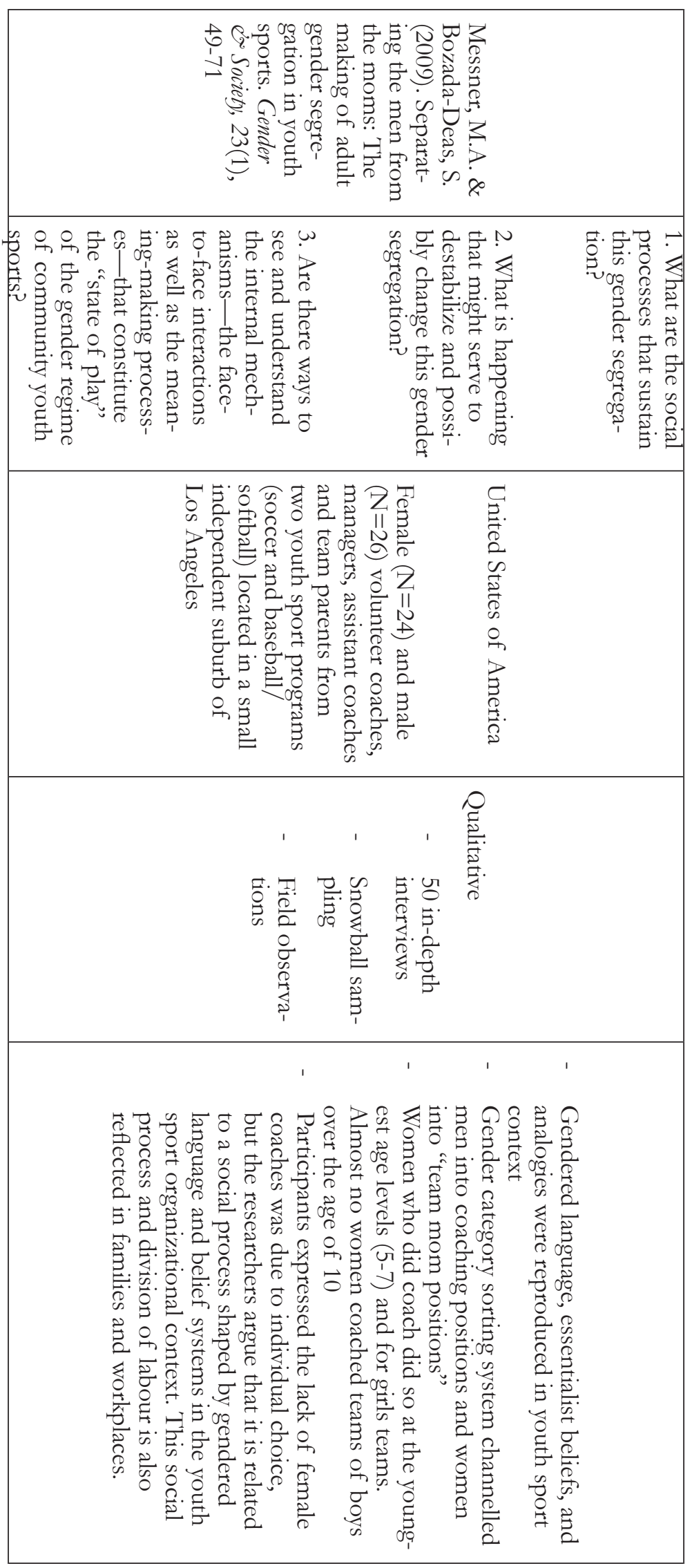




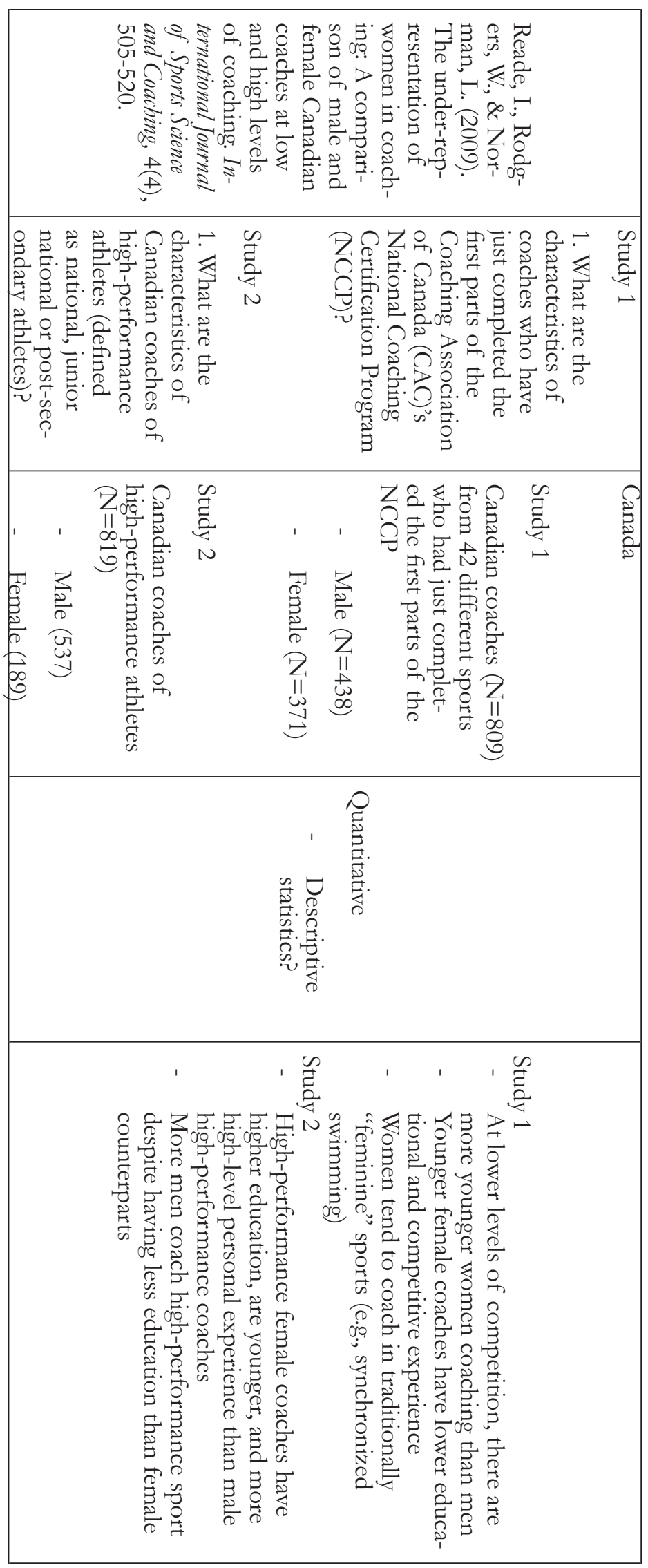

Journal of Amateur Spor

Volume Seven, Issue One

Baxter, 2021 


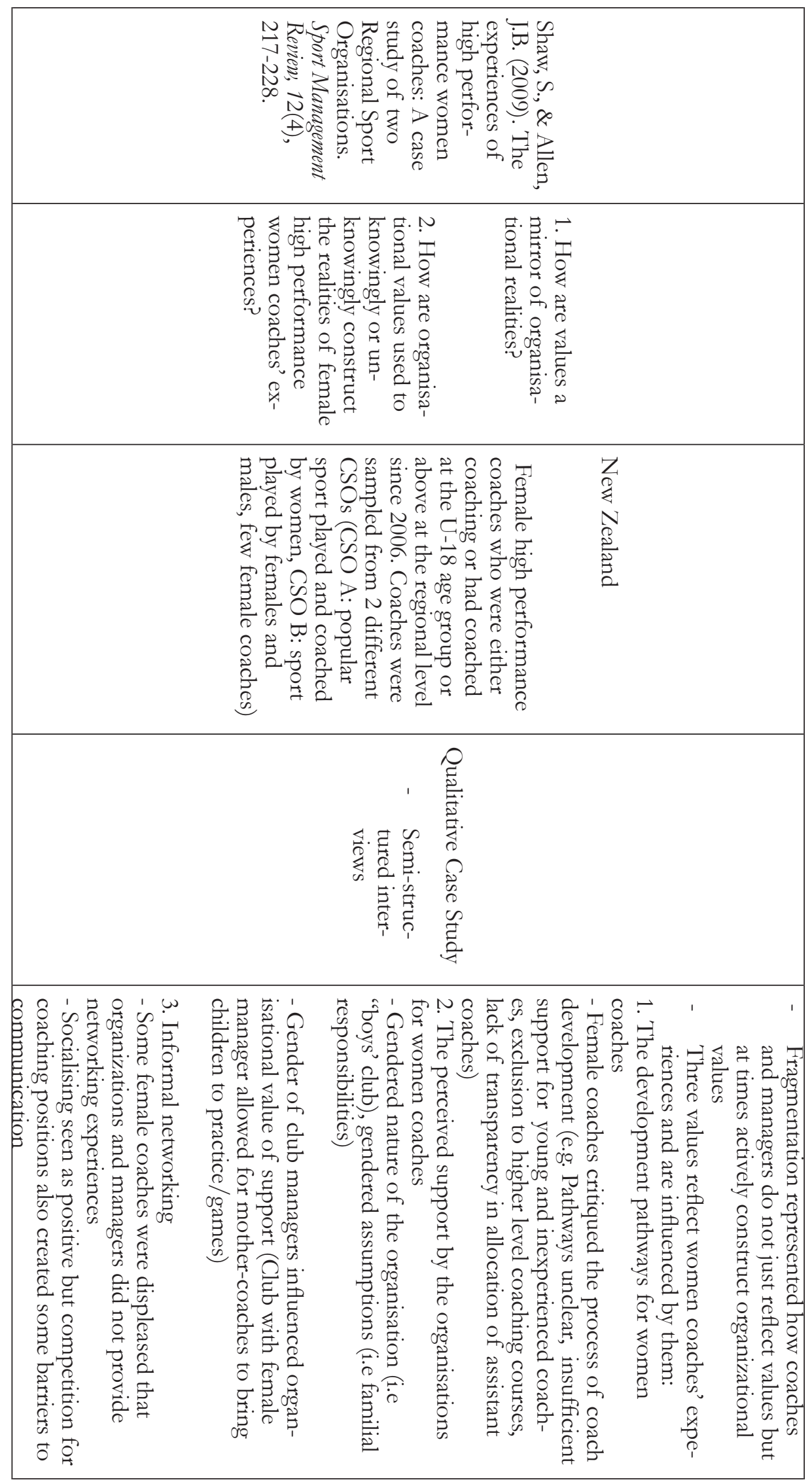

Journal of Amateur Sport Volume Seven, Issue One Baxter, 202179 


\begin{tabular}{|c|c|c|c|c|c|c|c|}
\hline & 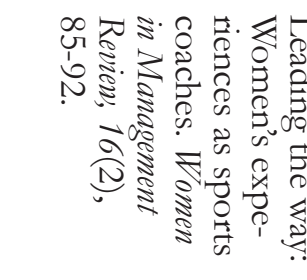 & 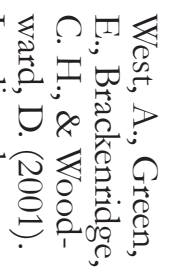 & & 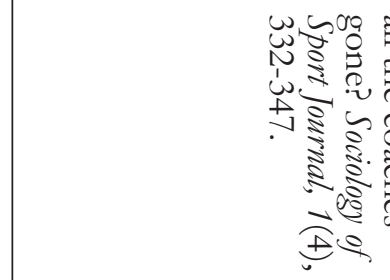 & 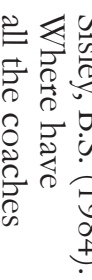 & & \\
\hline & 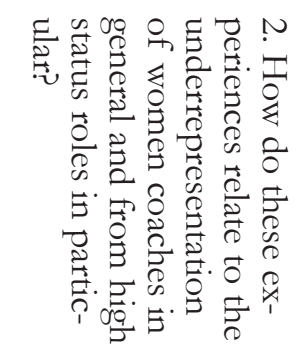 & 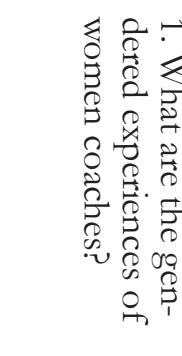 & & 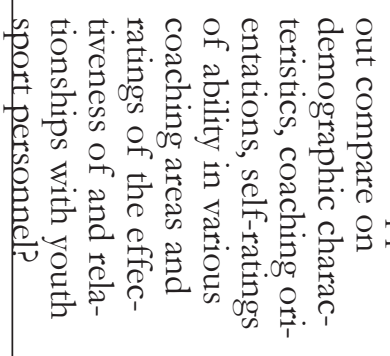 & 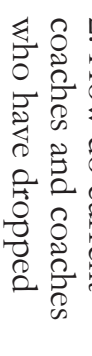 & & 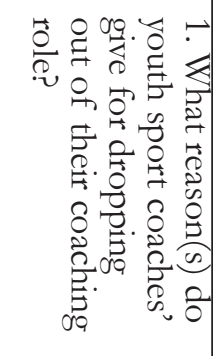 \\
\hline & 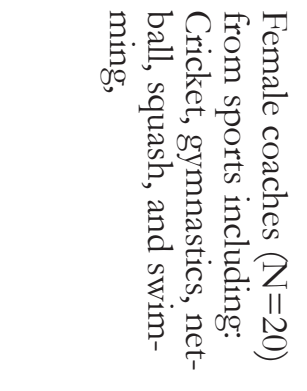 & 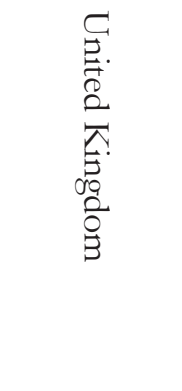 & & 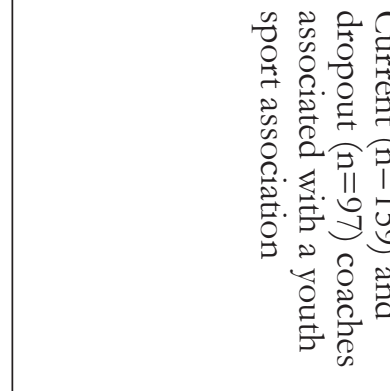 & & 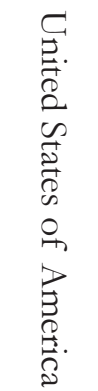 & \\
\hline & 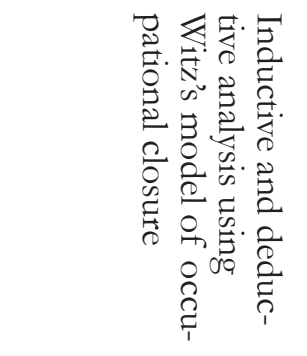 & 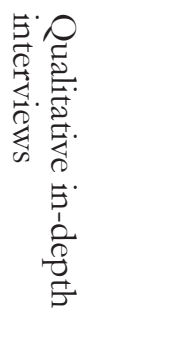 & & 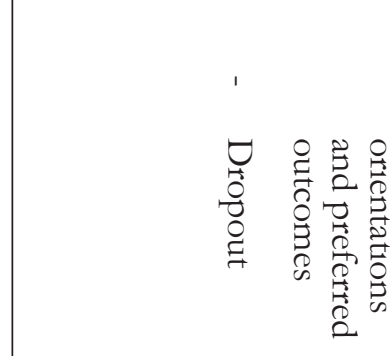 & 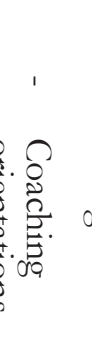 & 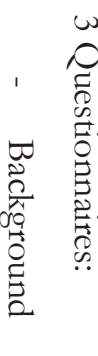 & 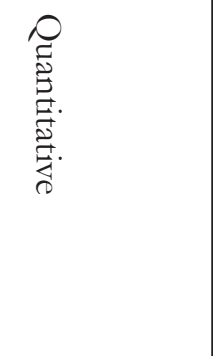 \\
\hline 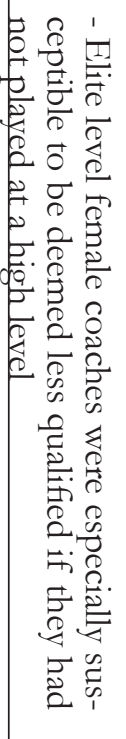 & 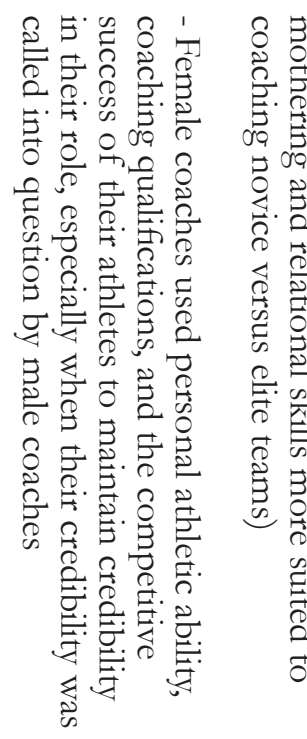 & 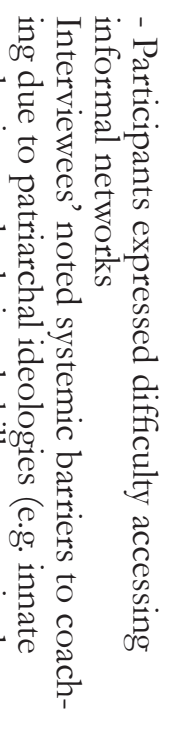 & 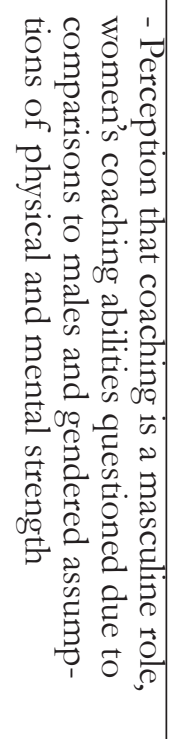 & 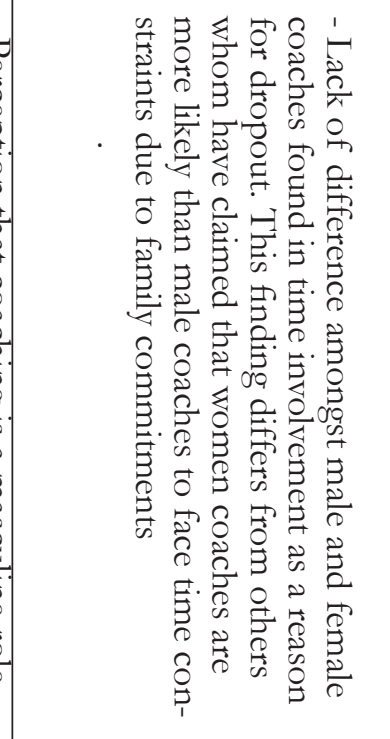 & 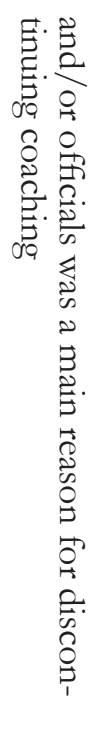 & 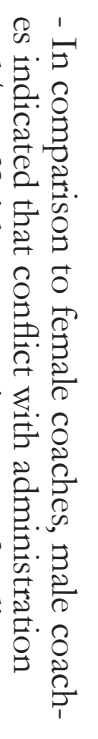 & 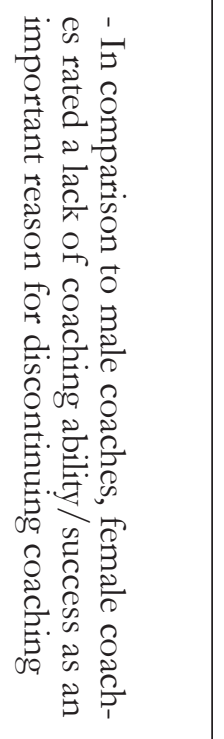 \\
\hline
\end{tabular}

Journal of Amateur Sport Volume Seven, Issue One Baxter, 202180 


\section{Thematic Analysis Findings}

The review process identified a total of five themes related to female volunteer community coaches: (1) motives, (2) barriers, (3) values, (4) supports, and (5) retention. While these themes are somewhat unsurprising and reflect the broader research field of sports coaching at all levels, what they reveal is a marked lack of empirical knowledge about female sport coaches at the community level.

\section{Motives}

The review identified a desire from researchers to understand what motivates women to pursue volunteer coaching positions. In a study conducted solely on females within the Norwegian Volleyball association, a distinguishing motivational factor specific to female volunteers was revealed. Hovden (1999) found that women were often initially motivated by aspirations to increase female representation in coaching and leadership positions and the desire to promote gender equality in sport. Studies in this review aimed at discovering motives $(\mathrm{N}=2)$ posed research questions related to volunteer motivation, but curiously the findings were clouded by discussion surrounding barriers, conflict, and dilemmas faced by female coaches. In a mixed sample of predominantly male $(\mathrm{N}=122)$ and female $(\mathrm{N}=19)$ youth soccer coaches, Busser and Carruther (2010) did not explicitly examine gender differences in volunteer motives. Findings revealed that an overwhelming number of volunteer coaches surveyed were motivated by their inherent values (altruism), the desire to foster positive youth development, instill positive values, and make a difference in the lives of players. These findings however may not reflect the specific motives of female coaches given the small sample of females surveyed in comparison to males.

\section{Barriers}

A prominent theme revealed in the review surrounded the multitude of barriers women face in their attempts to secure volunteer coaching roles. Barriers identified amongst the articles $(\mathrm{N}=5)$ include; role conflicts, gender category sorting (e.g. channelling men into coaching positions and women into administrative positions), patriarchal belief systems, not feeling empowered to raise or articulate interest or needs, and the perceived lack of female coach development (e.g. unclear coaching pathways, insufficient support for young and inexperienced coaches, exclusion to higher level coaching courses, lack of transparency in allocation of assistant coaches). When in coaching roles women also perceived a lack of organizational support due to the gendered nature of sport organisations (i.e. the dominance of a 'boys' club) and gendered assumptions (i.e. familial responsibilities) (Shaw \& Allen, 2009). Barriers were noted as intrinsically connected to the gendered experiences of female coaches. The aims of the studies and their theoretical frameworks employed varied. Examples of frameworks used include occupational sex-segregation (LaVoi, 2009), role triad (Leberman \& LaVoi, 2011), Witz's (1990;1992) model of occupational closure (West et al., 
2001), and division of labour (Messner \& Bozada-Deas, 2009). Despite the variety of frameworks used, research questions amongst the studies revealed two lines of inquiry related to gender: (1) gender segregation in coaching and (2) the social construction of gender roles in sport organizations.

Findings of gender segregation in coaching unveiled how women have been impeded from entering coaching positions. Messner and Bozada-Deas (2009) found that social processes sustain gender segregation through gendered language, essentialist beliefs, and analogies in the context of youth sport. Further, they found that men were more often channelled into coaching positions and women were encouraged to take on "team mom" roles as a result of gendered beliefs concerning division of labour. Participants in the study expressed that the lack of female coaches was due to individuals' choice, but the researchers argued that gendered language and social constructions of gender within the context of youth sport reflect the division of labour in families and the workplace (i.e. men as public sphere leaders, women as domesticated private sphere workers).

LaVoi (2009) examined gender segregation in volunteer coaching in two ways: tokenism and marginalization. Tokenism can occur when an individual from a less represented group are placed in a role in which they are subjected to scrutiny and pressure to conform to organizational norms (Kanter, 1977). Marginalization occurs when females are not allowed to participate or denied access to certain positions or are not provided with opportunities to develop within the organization (Allison, 2000). Findings revealed that female coaches were "tokens" on all boy's teams and high-level competitive girls' teams within the youth soccer association under investigation and were marginalized and underrepresented in all positions of power at almost all age groups and competitive levels (LaVoi, 2009). Both articles outline the barriers to coaching for female volunteers resulting from gender segregation.

The social construction of gender roles represents a larger systemic barrier for women wishing to pursue coaching roles. The construction of gender roles is highlighted in the research questions and findings in studies conducted by West et. al., (2001) and Leberman and LaVoi (2011). West et al., (2001) found that patriarchal ideologies (e.g. women have innate mothering and relational skills suited to coaching novice versus elite teams) led to underrepresentation of women coaches in higher status roles. Ideologies also generated the perception that coaching was a masculine role and female coaches' abilities were questioned due to gendered assumptions of physical and mental strength. In order to combat these ideologies, female coaches used their personal athletic ability, coaching qualifications, and the competitive success of their athletes to maintain credibility in their role, especially when their credibility was called into question by male coaches. Females who coached at elite levels were especially susceptible to critique if they had not played at a 
high level themselves in comparison to male coaches. In contrast to West et al.,'s critical analysis of the social construction of gender roles, Leberman and LaVoi (2009) focus specifically on the role triad of the mother-worker-coach. Findings suggest that mother-worker-coaches' saw the skills between roles as transferrable (e.g. interpersonal skills, care and compassion, organization and leadership abilities) and expressed that their reasons for coaching and notions of being a good mother were very similar (e.g. spending time together, role modeling, developing life skills). Tensions between mother-worker-coach roles were negotiated by selecting one and not the other, maintaining separate roles, neutralizing roles, or reframing the tension.

The prevalence of gender segregation and the socially constructed discourses surrounding gender roles in community sport, including that of the 'good mother', reflect prevailing norms and taken-for-granted truths surrounding gender. These statements, beliefs, and vocabularies become "partially true in terms of consequences" (Alvesson \& Billing, 1977). Research has outlined the consequences of minimal representation of female coaches; however, opportunity remains to challenge and change the ways in which gender research is theoretically informed in female volunteer coaching literature.

\section{Values}

Female coaches' perceptions of organisational values within CSOs was the focus of studies conducted by Shaw and
Allen (2009) and Allen and Shaw (2013). In their initial article, Shaw and Allen sought to identify how organisational values knowingly or unknowingly construct the realities of high-performance women coaches' experiences. Three values were identified as being reflective of female high-performance coaches' experiences and are influenced by them: (1) the development pathways for women coaches, (2) The perceived support by the organisational for women coaches, and (3) informal networking. These organizational values and how these values were constructed by coaches and managers were found to be fragmented. As a result of this fragmentation, multiple meanings through which people understood their organisational experience within CSOs led female coaches to report feeling that the gender of club managers influenced organisational values and support. For example, clubs with female managers allowed mother-coaches to bring their children to practices and games, which positively influenced mother-coaches perceptions of organisational support. Upon further exploration of perceptions of organisational values within CSOs, Allen and Shaw's (2013) study revealed that when organisational structures and values were not present, female coaches felt isolated, unsupported, disconnected from the organisation, and valued only as a functional role.

\section{Support}

Interest in gauging the perceptions female coaches have of feeling supported was reflected in the research questions of 
two of the journal articles in this review. The articles focused on understanding the psychological needs of coaches. Shaw and Allen (2009) used self-determination theory as a framework to analyse coaches' psychological needs, whereas Harman and Doherty (2014) used psychological contract theory to investigate coaches' perceptions of support. Shaw and Allen (2009) found differences in organizational environment and perceptions of support amongst female coaches. The study purposively sampled female coaches from two different CSOs. CSO A was a popular sport played and coached by women, whereas CSO B was a sport played by women and men, with few female coaches. Findings reveal that all female coaches desire a sense of relatedness amongst coaches and key CSO personnel in order to feel supported in their role. CSO A operated in an autonomy-supportive environment where female coaches felt a sense of relatedness. In comparison, the laissez-faire environment of CSO B was not conducive to female coaches feeling a sense of relatedness.

Harman and Doherty (2014) sought to establish whether the psychological contract of volunteer youth sport coaches varied by their gender, level of play (recreational, competitive) and/or tenure (novice, experienced). Variation was found amongst those who coached at different levels of play and coaching tenure but not gender. Interestingly, findings related to female coaches specifically found that $50 \%$ of female coaches in comparison to $75 \%$ of male coach- es indicated their expectation for club administration. Coaches' psychological contracts were also found to be shaped predominantly by sources external to the club (e.g. previous experience as a player/ coach, formal coaching course, personal philosophy, word of mouth, and other formal work roles). Findings amongst other articles in this review suggest female coaches face barriers accessing external sources such as formal coaching courses and word of mouth due to unclear pathways for development, exclusion to higher level coaching courses and limited access to informal networking due to the "boys club mentality" (Shaw \& Allen, 2009; West et al., 2001).

Female coaches report that opportunities for learning and development and interpersonal relationships with other coaches and leaders in the organisation were important factors to them feeling valued and supported in their role (Allen \& Shaw, 2013). The sole journal article featured in this review seeking to identify the characteristics and outcomes of mentoring relationships for female coaches found that an overwhelming 96\% of female coaches in Canada found mentorship helpful in supporting their development (Banwell et al., 2019). Characteristics of mentors were diverse and included both male and female mentors, informal and formal mentors, and mentors who were internal and external to the organisation they coached for (Banwell et al., 2019). Mentors came from all levels of coaching and had varied levels of expertise (house league, high school, community club, provincial, national, 
university, and international). Mentees described how mentors provided helpful guidance, especially early in their career development, by offering career related and transferable life skills through provision of advice, open communication, new challenging environments, and professional development opportunities (Banwell et al., 2019). Despite the described benefits of mentorship, participants identified a need to move beyond laid-back mentorship approaches and provide pro-active sponsorship of female coaches in order to advance women in coaching. Sponsorship entailed connecting female coaches to networks of people and providing knowledge about coaching opportunities (Banwell et al., 2019).

\section{Retention}

The continual decline in volunteer coaches is concerning for non-profit sport organizations (Hoye et al., 2020). Retention of volunteer coaches is particularly low amongst female volunteer coaches. Research seeking to understand gender differences in volunteer retention found that $70 \%$ of male coaches volunteering for a municipal soccer program coached beyond their first year in comparison to only $28 \%$ of female coaches (Busser \& Carruthers, 2010). Factors leading female coaches to drop out of their coaching role included perceived lack of ability and success, and belief that they were less knowledgeable about sport than others (Busser \& Carruthers, 2010; Weiss \& Sisley, 1984). While studies not included in this review have claimed that time involvement led to issues retaining female coaches, Weiss and Sisley (1984) found no difference amongst male and female coaches. Identifying reasons for discontinuing coaching has implications for the retention of female volunteer coaches.

\section{Future Directions and Emergent Areas of Research}

This scoping review has established that empirical research articles on female volunteer community sport coaches are few and far-between. The limited amount of literature in this area offers several points of discussion, as well as opportunities for emergent areas of research. Previous research on female volunteer community sport coaches has demonstrated that the sport coaching environment is not a positive, nor welcoming environment for many female coaches. The patterns of sport delivery often lack flexibility, leading to poorly designed programs that do not facilitate the involvement of female volunteer coaches. For example, rigid scheduling of organized sport may not be inclusive of working professionals whose income-earning activities are outside of traditional, long-term employer-employee relationships and/or women with familial commitments (i.e. those who care for older adult family members or serve as the primary childcare provider). Echoing the statements of LaVoi et al. (2019), researchers must move beyond identifying barriers and instead focus on what forms of support are needed to overcome these barriers in order for women coaches to 
succeed. Reiterating perennial issues on women in coaching will do little for addressing the concerning and often times taken-for-granted structures, policies, behaviours, and management approaches in sport that lead to marginalization and the perpetuation of male hegemony (Shaw \& Allen, 2009; Fink, 2008).

Forms of support within sport structures, policies, behaviours, and management approaches need to be identified and implemented to create a better experience for female volunteer coaches. Several topics from the broader coaching literature were not addressed in the extant research on female volunteer community sport coaches and may help generate new knowledge to improve the experiences of female coaches, specifically: recruitment, coaching pathways, performance, stress and well-being, and policy and governance. Cunningham and Sagas (2008) call for attention to be paid to new contexts, subjects, and multi-level influences to produce theoretical development. Researchers wishing to conduct research within the themes identified in this review must consider the importance of building theory. No studies in this review contributed to the development of theory but instead applied existing theoretical frameworks or produced atheoretical research. Future research should use theory as a way to formulate research questions and develop innovative methods in order to both develop existing theoretical frameworks and inform practice (Cunningham, 2013).

We offer the following suggestions for future research, organised around eight specific topics, each with suggested questions (see Table 2): policy and governance, coaching pathways, recruitment, retention, performance, stress and wellbeing, values, and support. Understanding more about the policies that either support or suppress the involvement and experience of women in volunteer community sport coaching roles is important in order to inform policy makers, sport organizations and coaching associations to address policy shortcomings or create policies that actively seek to address the shortfall of female volunteer coaches. Females should also be central to the governance of community sport and to the organizations that facilitate community sport coaching, we emphasise the need for further research in this specific field.

This review has highlighted the challenges faced by females in progressing through the traditional coaching pathways. More research is required to understand their experiences of these pathways, how CSOs can support them better and what might need to be changed to increase the number of females coaching within community sport and the quality of their experience. We also need to know far more about the motives of females seeking to coach at the community levels of sport and how to recruit females into these coaching roles, the perceptions of young female athletes about future coaching roles, and how to tailor the recruitment message for females.

The dearth of research into retention strategies has been highlighted earlier so we propose future research efforts should focus on understanding what retention strategies could be effective in 
retaining female volunteer community coaches, or indeed, supporting previous coaches or athletes return to a coaching role. We also know very little about female volunteer community coaches' attitudes to coaching performance or the assessment of their own performance and thus pose several questions on performance in the context of community sport. Similarly, we know very little about stress and well-being amongst female volunteer community coaches or the support systems that might address these issues but also broader issues of career progression and how shifting organisational values and implementing support systems might overcome gender biases or other constraints and barriers identified as part of this scoping review. Drawing upon directives from the authors of articles included in this review and our own reflections, we propose a number of research questions on each of these topics as suggestions for future research.

Considering the lack of innovative methodology in the studies included in this review, researchers should consider incorporating methods that contribute to meeting the call for contemporary approaches to qualitative research (Hoeber $\&$ Shaw, 2016). In addition, more advanced quantitative research is needed to update the somewhat dated demographic data on volunteer coaches and contribute to the development of a theoretically driven understanding of the experiences of female volunteer coaches. Comparative studies at the local, regional, national, and international level may also add to our understanding of how sport sys- tems, structures, governing bodies, and policies are supporting or can support female volunteer coaches within community sport. Longitudinal study designs could foster a greater understanding of factors related to recruitment, retention, and support of female volunteer coaches over time. There is considerable scope to utilise interventions and experimental research designs that could contribute to implementing changes in practice by assessing the value of creating better experiences for female volunteer coaches within community sport.

As Harman and Doherty (2014) note, coaches are not a homogenous group. Coaches have different expectations of themselves, motives for coaching, and desire for particular forms of support. Research on female volunteer community sport coaches should also be conscious of exploring the plurality of experiences amongst females. Future research should seek to incorporate different voices, especially those who have intersectional identities (Banwell et al., 2019; LaVoi, 2019). This will contribute to a greater understanding of the various experiences of female sport coaches and ways in which CSOs and sport governing bodies can support their involvement.

It is important to note that of the empirical studies identified, no articles focused solely on female volunteer coaches within community sport. The sample of female volunteer coaches included in broader studies were often small, providing little insight on the voluntary nature of their coaching role. This hinders our understanding of the factors influenc- 


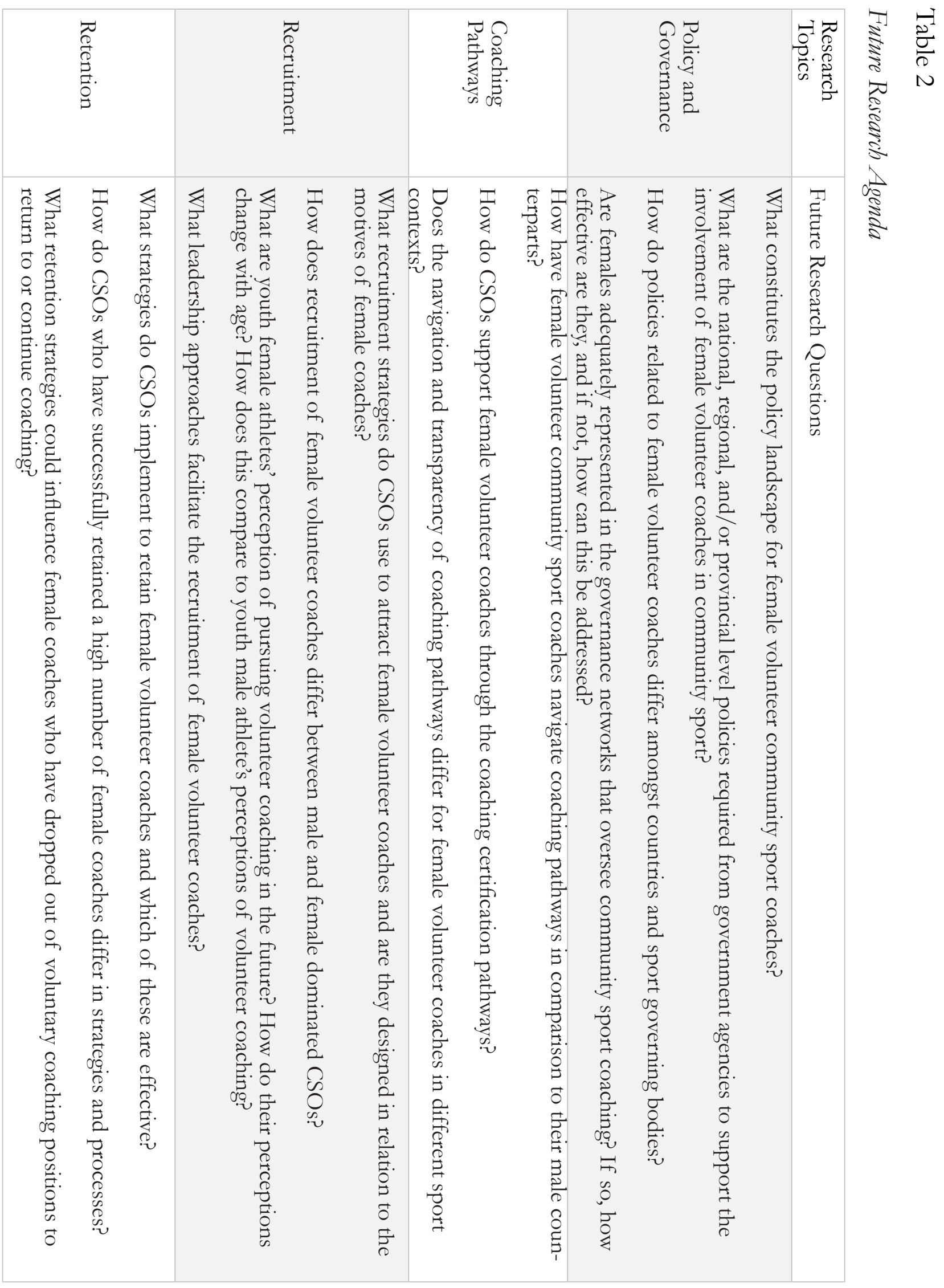




\begin{tabular}{|c|c|c|c|c|c|c|c|c|c|c|c|}
\hline & 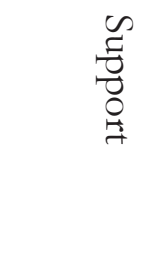 & & & & & & 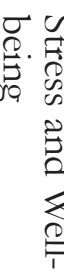 & & & 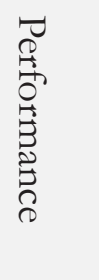 & \\
\hline 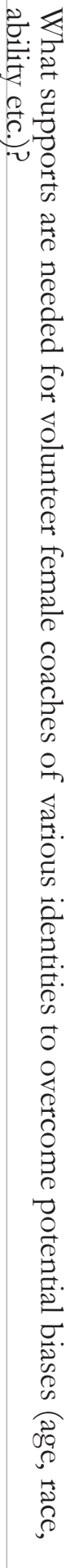 & 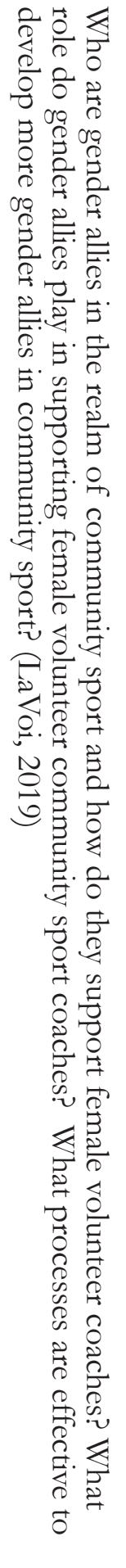 & 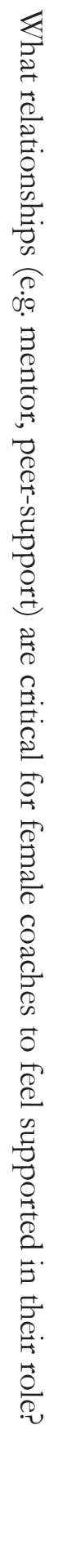 & 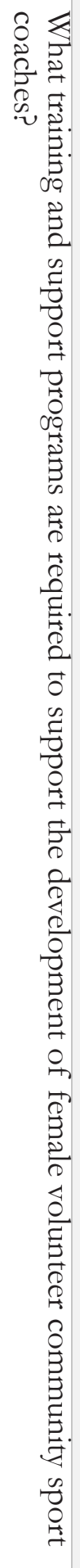 & 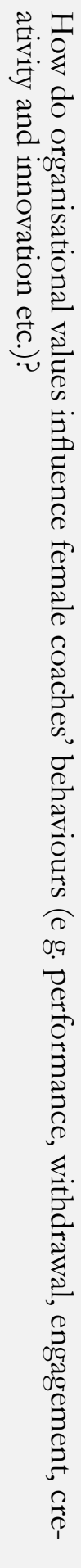 & 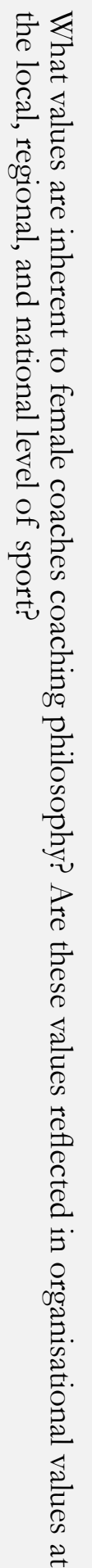 & 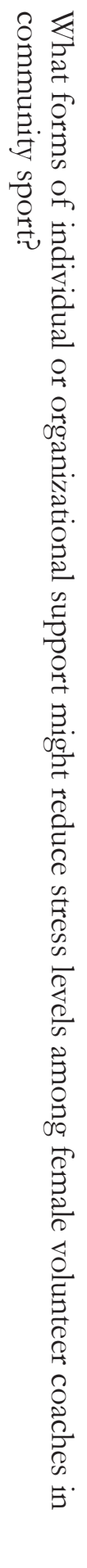 & 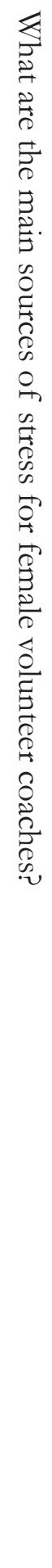 & 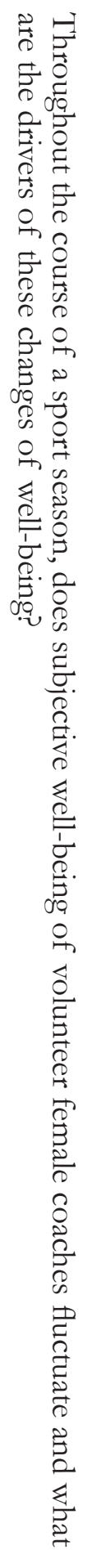 & 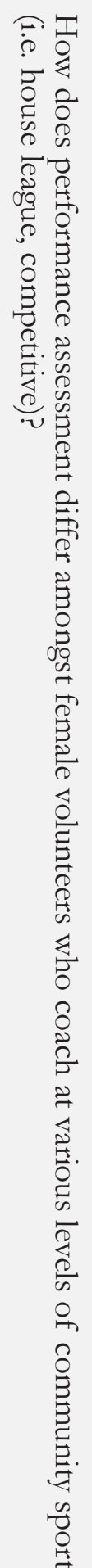 & 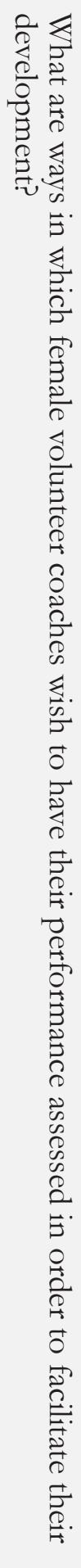 & 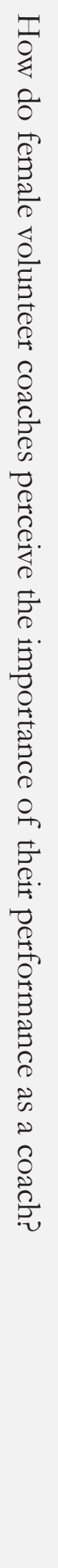 \\
\hline
\end{tabular}


ing the experience and management of female volunteer community sport coaches. Most of the research to date on female coaches has focused on increasing representation of female coaches at elite or paid levels of sport. While a worthy pursuit, the representation of women at the community level should be of equal concern. Given the non-profit, volunteer driven structure of community sport in countries such as Canada, Australia, and the UK, understanding how to best manage and support volunteer involvement is 'crucial for the sustainability of the sport sector' (Hoye et al., 2020). It is important that research not conflate female volunteer coaches' experiences with the experiences of females who pursue coaching as a paid career. Females need not always follow a linear pathway into an elite level or paid coaching roles. Instead opportunities for all coaching pathways (volunteer and paid) should be made transparent so female coaches can choose what best suits their desired degree of involvement. Our hope is future research on female volunteer coaches can contribute to efforts to challenge gender roles and increase diversity amongst volunteer sport coaches within community sport.

\section{References}

Allen, J. B., \& Shaw, S. (2009). Women Coaches' Perceptions of their Sport Organizations' Social Environment: Supporting Coaches' Psychological Needs? The Sport Psychologist, 23, 346-366. https://doi/org/10.1123/ tsp.23.3.246
Allen, J. B., \& Shaw, S. (2013). An Interdisciplinary Approach to Examining the Working Conditions of Women Coaches. International Journal of Sports Science \& Coaching, 8(1), 1-17. https:// doi.org/10.1260/1747-9541.8.1.1

Arksey, H., \& O’Malley, L. (2005). Scoping Studies: Towards a Methodological Framework. International Journal of Social Research Methodology, 8(1), 19-32. https://doi. org/10.1080/1364557032000119616

Banwell, J., Kerr, G., \& Stirling, A. (2019). Key Considerations for Advancing Women in Coaching. Women in Sport \& Physical Activity Journal., 27(2), 128-135. https://doi. org/10.1123/wspaj.2018-0069

Bruening, J., \& Dixon, M. (2008). Situating Work-Family Negotiations within a Life Course Perspective: Insights on the Gendered Experiences of NCAA Division I Head Coaching Mothers. Sex Roles, 58(1-2), 10-23. https://doi. org/10.1007/s11199-007-9350-x

Busser, J. A., \& Carruthers, C. P. (2010). Youth Sport Volunteer Coach Motivation, Managing Leisure, 15(1), 128-139, https://doi. org $/ 10.1080 / 13606710903448210$

Cunningham, G., \& Sagas, M. (2008). Gender and Sex Diversity in Sport Organizations: Introduction to a Special Issue. Sex Roles, 58(1-2), 3-9. https://doi.org/10.1007/s11199-0079360-8

Cunningham, G. (2013). Theory and Theory Development in Sport Management. Sport Management Review, 
16(1), 1-4. https://doi.org/10.1016/j. smr.2012.01.006

Cuskelly, G., Taylor, T., Hoye, R., \& Darcy, S. (2006). Volunteer Management Practices and Volunteer Retention: A Human Resource Management Approach. Sport Management Review, 9(2), 141-163. https://doi.org/10.1016/ S1441-3523(06)70023-7

Cuskelly, G. (2011). Sport volunteers literature review for the Australian Sports Commission. https:// www.clearinghouseforsport. gov.au/_data/assets/pdf_ file/0004/596479/2014_097411_D_ ASC_Sport_Volunteers_Literature_ Review_Final2.pdf

Dixon, M., \& Sagas, M. (2007). The Relationship Between Organizational Support, Work-Family Conflict, and the Job-Life Satisfaction of University Coaches. Research Quarterly for Exercise and Sport, 78(3), 236-247. https://doi/ abs/10.1080/02701367.2007.1059942 1

Dowling, M., Leopkey, B., \& Smith, L. (2018). Governance in Sport: A Scoping Review. Journal Of Sport Management, 32(5), 438-451. https://doi. org/10.1123/jsm.2018-0032

Drey, N., Gould, D., \& Allan, T. (2009) The Relationship between Continuing Professional Education and Commitment to Nursing. Nursing Education Today, 29, 740-745. https://doi. org/10.1016/j.nedt.2009.03.008

Everhart, C., \& Chelladurai, P. (1998). Gender differences in Preferences for Coaching as an Occupation: The
Role of Self-Efficacy, Valence, and Perceived Barriers. Research Quarterly for Exercise and Sport, 69(2), 188-200. https://doi.org/10.1080/02701367.1 998.10607683

Fink, J. (2008). Gender and Sex Diversity in Sport Organizations: Concluding comments. Sex Roles, 58(1-2), 146-147. https://doi.org/10.1007/ s11199-007-9364-4

Fraser-Thomas, J., Côté, J., \& Deakin, J. (2007). Understanding Dropout and Prolonged Engagement in Adolescent Competitive Sport. Psychology of Sport \& Exercise, 9(5), 645-662. https://doi.org/10.1016/j. psychsport.2007.08.003

Government of Canada. (2015). Actively engaged: A policy on sport for women and girls. http:/ / canada.pch.gc.ca/ eng/1414511367652/1414602693839

Harman, A., \& Doherty, A. (2014). The Psychological Contract of Volunteer Youth Sport Coaches. Journal of Sport Management, 28(6), 687-699. https:// doi.org/10.1123/JSM.2013-0146

Hoeber, L., \& Shaw, S. (2016). Contemporary Qualitative Research Methods in Sport Management. Sport Management Review, 20(1), 4-7. https://doi. org/10.1016/j.smr.2016.11.005 Hogan, D.B., Maxwell, C.J., Afilalo, J., Bagshaw, S. M., Barsan, J., Dergman, H., Carter, C., Dixon, E., Hemmelgarn, B., Madden, K.., Mitinitski, A., Rolfson, D., Stelfox, H., Tam-Tham, H., Wunsch, H. (2017). A Scoping Review of Frailty and Acute Care in Middle-Aged and Older Indi- 
viduals with Recommendations for Future Research. Canadian Geriatrics Journal, 20, 22-37. https://dx.doi. org $/ 10.5770 \% 2$ Fcgj. 20.240

Hovden, J. (1999). Is it Worth the Price? Women's Involvement in Leadership and Coaching in Sports Organizations in Norway. Women in Sport and Physical Activity Journal, 8(1), 23-45. https:// doi.org/10.1123/wspaj.8.1.23

Hoye, R., Cuskelly, G., Auld, C., Kappelides, P., \& Misener, K. (2020). Sport Volunteering. Routledge.

Hudani, Z., \& Rojas-Fernandez, C. (2016). A Sscoping Review on Medication Adherence in Older Patients with Cognitive Impairment or Dementia. Research in Social and Administrative Pharmacy, 12(6), 815-829. https://doi.org/10.1016/j.sapharm.2015.11.011

Inoue, Y., Berg, B., \& Chelladurai, P. (2015). Spectator Sport and Population Health: A Scoping Study. Journal of Sport Management, 29(6), 705-725. https://doi.org/10.1123/JSM.20140283

Krustrup, P., \& Parnell, D. (2018). Sport and Health: Exploring the Current State of Play . Routledge. https://doi. org/10.4324/9781315266459

LaVoi, N. M.. (2009). Occupational Sex Segregation in a Youth Soccer Organization: Females in Positions of Power. Women in Sport \& Pbysical Activity Journal, 18, 25-37. https://doi. org/10.1123/wspaj.18.2.25

LaVoi, N. M. (2016). Women in Sports Coaching. (1st ed., Routledge Research in Sports Coaching Series).
LaVoi, N. M., \& Dutove, J. K.. (2012) Barriers and Supports for Female Coaches: An Ecological Model, Sports Coaching Review, 1(1), 17-37. https:// doi.org/10.1080/21640629.2012.695 891

LaVoi, N. M., McGarry, J. E., \& Fisher, L. A. (2019). Final Thoughts on Women in Sport Coaching: Fighting the war. Women in Sport \& Physical Activity Journal, 27(2), 136-140. https:/ / doi.org/10.1123/wspaj.2019-0030

Leberman, S. I., \& LaVoi, N. M. (2011). Juggling Balls and Roles, Working Mother-Coaches in Youth Sport: Beyond the Dualistic Worker-Mother Identity, Journal of Sport Management, 25(5), 474-488. https:/ / doi. org/10.1123/jsm.25.5.474

Levac, D., Colquhoun, H., \& O’Brien, K. K.. (2010). Scoping Studies: Advancing the Methodology. Implementation Science, 5(69). https://doi. org/:10.1186/1748-5908-5-69

Messner, M. A., \& Bozada-Deas, S. (2009). Separating the Men from the Moms: The Making of Adult Gender Segregation in Youth Sports. Gender \& Society, 23(1), 49-7. https://doi. org $/ 10.1177 \% 2 F 0891243208327363$

Misener, K., \& Doherty, A. (2013). In Support of Sport: Examining the Relationship between Community Sport Organizations and Sponsors. Sport Management Review, 17(4), 493-506. https://doi.org/10.1016/j. smr.2013.12.002

Moran-Miller, K., \& Flores, L. (2011). Where are the Women in Women's Sports? Predictors of Female Ath- 
letes' Interest in a Coaching Career. Research Quarterly for Exercise and Sport, 82(1), 109-117. https://doi.org/10.10 80/02701367.2011.10599727

Peterson, J., Pearce, P., Ferguson, L., \& Langford, C. (2017). Understanding Scoping Reviews: Definition, Purpose, and Process. Journal of the American Association of Nurse Practitioners, 29(1), 12-16. https:/ / doi. org/10.1002/2327-6924.12380

Physical Activity Monitor Survey. (2010). Sport participation 2010 research paper. http://publications.gc.ca/collections/ collection_2013/pc-ch/CH24-12012-eng.pdf

Reade, I., Rodgers, W., \& Norman, L. (2009). The Under-Representation of Women in Coaching: A Comparison of Male and Female Canadian Coaches at Low and High Levels of Coaching. International Journal of Sports Science and Coaching, 4(4), 505-520. https://doi.org/10.1260\% 2F174795409790291439

Ronkainen, N., Ryba, T., \& Selänne, H. (2019). "She is Where I'd Want to be in my Career": Youth Athletes' Role Models and their Implications for Career and Identity Construction. Psychology of Sport \& Exercise, 45 1-8. https://doi.org/10.1016/j. psychsport.2019.101562 Ruiz, J., Quackenboss, J., \& Tulve, N. (2016). Contributions of a Child's Built, Natural, and Social Environments to their General Cognitive Ability: A systematic Scoping Review. PLoS One, 11(2), 1-44. https://doi.org/10.1371/journal. pone. 0147741

Shaw, S, \& Allen, J. B. (2009). The Experiences of High Performance Women Coaches: A Case Study of Two Regional Sport Organisations. Sport Management Review., 12(4), 217228. https://doi.org/10.1016/j. smr.2009.03.005

Sport England. (2019). Active lives adult survey: May 18/19 report. https:/ / sportengland-production-files. s3.eu-west-2.amazonaws.com/ s3fs-public/2020-01/active-livesadult-may-18-19-report_1.pdf?ehS517YBm3YeLHgNwXLmUSbTZPENafJY

Sport New Zealand Group. (2019). Sport New Zealand girls and young women profile. https://sportnz.org.nz/assets/ Uploads/Girls-and-Young-WomenProfile-.pdf

Stirling, A., Kerr, G., Banwell, J., MacPherson, E., \& Jewett, R. (2017). A Mentorship Guide for Advancing Women in Coaching: Effective Mentoring Practices for the Mentee. https://www.coach.ca/files/Mentee_ Guide_EN.pdf

Stukas, A., Hoye, R., Nicholson, M., Brown, K., \& Aisbett, L. (2014). Motivations to Volunteer and Their Associations with Volunteers' Well-Being. Nonprofit and Voluntary Sector Quarterly, 45(1), 112-132. https:/ / doi. org/10.1177/0899764014561122

Trussell, D. (2016). Young people's Perspectives of Parent volunteerism in Community Youth Sport. Sport Management Review, 19(3), 332-342. https://doi.org/10.1016/j. 
smr.2015.09.001

United States Bureau of Labor Statistics. (2015). Main volunteer activity for main organization for which activities were performed and selected characteristics. https:// www.bls.gov/news.release/volun.t05. htm

Weiss, M. R., \& Sisley, B. S. (1984). Where Have All The Coaches Gone? Sociology of Sport Journal, 1(4), 332-347 https://doi.org/10.1123/ssj.1.4.332

West, A., Green, E., Brackenridge, C. H., \& Woodward, D. (2001). Leading the Way: Women's Experiences as Sports Coaches. Women in Management Review, 16(2), 85-92. https:/ / doi. org/10.1108/09649420110386610

Wicker, P. (2017). Volunteerism and volunteer management in sport. Sport Management Review, 20(4), 325-337. https://doi.org/10.1016/j. smr.2017.01.001

Womens Sports Foundation. (2018). Teen sport in America: Why participation matters. https://www.womenssportsfoundation.org/wp- content/uploads/2018/01/teen-sport-in-america-full-report-web.pdf 